\title{
Relationship Between Food Insufficiency and HIV Infection Among Caregivers of Orphans and Vulnerable Children in Tanzania
}

This article was published in the following Dove Press journal: HIVIAIDS - Research and Palliative Care

\author{
Amon Exavery (iD) \\ John Charles' \\ Erica Kuhlik ${ }^{2}$ \\ Asheri Barankena' \\ Godfrey Martin Mubyazi ${ }^{3}$ \\ Levina Kikoyo' \\ Elizabeth Jere'
}

'Pact, Dar es Salaam, Tanzania; ${ }^{2}$ Pact, Inc., Washington, DC 20036, USA; ${ }^{3}$ National Institute for Medical Research (NIMR),

Dar es Salaam, Tanzania
Correspondence: Amon Exavery Email aexavery@pactworld.org
Background: Although Tanzania experiences a general decline in HIV prevalence, some populations such as caregivers of orphans may be at a higher risk than the general population, suggesting that infection pathways still need further exploration. This study examines how food insufficiency relates to HIV infection among caregivers of orphans and vulnerable children (OVC) in Tanzania.

Data and Methods: Data are from a community-based, USAID-funded Kizazi Kipya project that aims at increasing the uptake of HIV services, as well as other health and social services by OVC and their caregivers in Tanzania. Caregivers who were enrolled in the project from January to July 2017 in seven regions of Tanzania, and had reported their HIV status to the project, were included in the analysis. While HIV status was the outcome, the main independent variable was food insufficiency which was assessed using the Household Hunger Scale (HHS). Using Stata (version 14.0; StataCorp LP, College Station, TX, USA), data analysis involved multilevel mixed-effects logistic regression..

Results: Of the 47,617 caregivers analyzed (73.7\% females), $61.8 \%$ and $4.6 \%$ were experiencing moderate and severe hunger, respectively. The overall HIV prevalence among the caregivers was $28.3 \%$. Nevertheless, the prevalence was as high as $34.2 \%$ among caregivers in severe hunger households. Multivariate analysis revealed an increasing likelihood of being HIV positive as hunger increased (moderate hunger: $\mathrm{OR}=1.10,95 \% \mathrm{CI}$ : $1.03-1.18$; severe hunger: $\mathrm{OR}=1.51,95 \% \mathrm{CI}: 1.32-1.74)$. These observations were adjusted for marital status, age, sex, education, place of residence, family size, disability status, and health insurance.

Conclusion: Food insufficiency is associated with a higher likelihood of HIV infection among OVC caregivers in Tanzania, suggesting that improving access to adequate food has a potential to reduce HIV risks among them. Furthermore, food insufficiency could be considered an important criterion for targeting HIV testing and treatment services to expand coverage.

Keywords: food insufficiency, food security, HIV, caregivers of orphans and vulnerable children, USAID Kizazi Kipya, Tanzania

\section{Introduction}

HIV remains the biggest public health concern in Tanzania and a critical issue globally. In 2018, an estimated 1.6 million Tanzanians were living with HIV. This represented a HIV prevalence of $4.6 \%$ among adults ages $15-49$ years. ${ }^{1}$ In the same year, 72,000 Tanzanians were newly infected with HIV, and 24,000 AIDSrelated deaths were recorded. ${ }^{1}$ Although the country has experienced a general decline in the prevalence of HIV/AIDS (eg from $7.0 \%$ in $2005^{2}$ to $4.7 \%$ in $2017^{3}$ 
among 15-49 year-olds), the epidemic is generalized as it affects all population segments. Global responses to the HIV epidemic are challenged by new infections. ${ }^{4}$ Although the rate of occurrence of new infections has been declining since 2010, the decline is considered too slow to reach the UNAIDS' global target of 500,000 by $2020 .^{5}$

More than $80 \%$ of the HIV infections in Tanzania spread heterosexually, ${ }^{6,7}$ with contextual diversities pedaling the spread. ${ }^{8}$ This is evidenced by the fact that some population groups have higher HIV prevalence than others. Extant data show that while $4.6 \%$ of the general adult population are living with HIV in Tanzania, ${ }^{1}$ there exists a prevalence of up to $42 \%$ among people who inject drugs, ${ }^{9} 31.4 \%$ among female sex workers, ${ }^{10}$ and $30.2 \%$ among men who have sex with men. ${ }^{11}$ It has thus been recommended that HIV/AIDS prevention strategies must primarily focus on traditionally high-risk populations, and secondarily on unsafe health-care procedures in relatively preserved sub-Saharan areas. ${ }^{12}$

Many factors account for the variations in HIV prevalence in different populations. The risk factors for HIV acquisition are well documented, including biological sex, ${ }^{13}$ age, marital status, education, multiple sexual partners, unprotected sex, ${ }^{13,14}$ and alcohol consumption. ${ }^{13}$ Other factors include substance use, ${ }^{15}$ and transactional sex. ${ }^{16,17}$ The literature further reveals that the HIV epidemic is driven by limited HIV infection prevention services, social stigma, and the lack of human rights protection. ${ }^{8}$ In southern Africa, the epidemic is driven by high rates of labor migration, concurrent sexual partnerships, gender inequalities, and limited availability of male condoms. ${ }^{8}$ A study among street youths in Zambia found that lack of a home to return to, misconceptions about HIV/AIDS, and parental drug misuse increased HIV prevalence among the youths. ${ }^{18}$

Although many studies had analyzed factors associated with HIV in different populations, such evidence is missing for caregivers of orphaned and vulnerable children (OVC). Caregivers constitute a very important part of the population in the community. Given that HIV/AIDS alters family structures resulting from the death of adult children in the family, older persons become responsible for providing care (ie caregivers) to orphaned children. Consequently, the number of grandparents caring for AIDS orphans in developing countries has doubled over the last ten years. ${ }^{19}$ It has been further observed that the majority of the caregivers are women who face serious financial, physical, and emotional stress due to their caregiving obligations. ${ }^{19}$ This spurs their vulnerability, as well as the likelihood of experiencing food insufficiency due to additional economic pressure in the course of caring for OVC. ${ }^{20}$ Therefore, a full response to the needs of children requires considerable support for their caregivers in the first place. ${ }^{21}$

In 2014, the UNAIDS introduced the 90-90-90 global targets to end the AIDS epidemic, envisioning that, by $2020,90 \%$ of people living with HIV will know their HIV status, $90 \%$ of people who know their HIV-positive status will be accessing treatment, and $90 \%$ of people on treatment will have suppressed viral loads. ${ }^{5}$ Tanzania has made considerable progress towards the achievement of the targets in adults: $61-94-87 .^{3}$ Although the first 90 is the entry point to the subsequent $90 \mathrm{~s}$ in the cascade, a notable performance gap remains with it, suggesting that barriers to HIV testing still exist. Therefore, the aim of this study was to identify factors associated with HIV infection among caregivers of OVC in Tanzania. Knowledge of these factors is imperative to inform focused HIV testing strategies to improve the yield in the first 90. Understanding risk factors for HIV acquisition and transmission is important to planning appropriate interventions. ${ }^{22}$

\section{Data and Methods}

\section{Data Source}

This study is based on monitoring and evaluation data from a community-based, USAID-funded Kizazi Kipya project in Tanzania. The USAID Kizazi Kipya project (2016-2021) seeks to scale-up the uptake of HIV services, as well asother health and social services by OVC and

Table I USAID Kizazi Kipya Project Beneficiary Screening and Enrollment Criteria

I. Household is headed by child (under 18 years old)

2. Household is headed by an elderly caregiver (60 years or older)

3. Household cares for one or more single or double orphans

4. Caregiver is chronically ill and unable to meet basic needs of children

5. Caregiver is a drug user

6. Caregiver or adolescent aged 10-19 in household is a sex worker

7. At least one adolescent girl aged 10-19 who in the household is sexually active

8. Adolescent girl aged 10-19 in the household is pregnant or has a child of her own

9. At least one household member is HIV positive

10. At least one child in the household has tuberculosis (TB)

II. At least one child in the household is severely malnourished

12. At least one child in the household has been or is being abused or is at risk of abuse

13. At least one child is living and or working on the streets

14. At least one child in the household is working in mines. 
their caregivers in the country. Data were self-reported by the caregivers of OVC to Community Case Workers (CCWs) during beneficiary screening and enrollment using the project's screening, enrollment, and Family and Child Asset Assessment (FCAA) tools from January to July 2017. Beneficiaries were enrolled into the project if their household met one or more of the 14 HIV-related household vulnerabilities in Table 1 .

For each enrolled household, the USAID Kizazi Kipya project through its CCWs and lead case workers develops a care plan for each household member. The project then provides or links the caregivers as well as the OVC to various health and social services including HIV, nutrition, education, child protection, social protection, and economic strengthening depending on established needs during care plan development. The project provides psychosocial support, nutrition assessments, counseling and support, referrals and linkages, and care plan monitoring. ${ }^{23}$ The project also tracks antiretroviral therapy (ART) use and adherence among its HIV-positive beneficiaries.

\section{Study Area}

Respondents for this study are from 24 councils in seven regions of Tanzania where the USAID Kizazi Kipya project had enrolled beneficiaries from January to July 2017. The regions are Dar es Salaam, Iringa, Kagera, Mara, Mtwara, Rukwa, and Singida.

\section{Study Design}

This study is a cross-sectional secondary analysis of existing enrollment data of the USAID Kizazi Kipya project described above. FCAA data were collected during screening and enrollment of beneficiaries. Beneficiary households meeting at least one of the enrollment criteria listed in Table 1 and had consented to participate, were enrolled in the program.

\section{Study Population}

We analyzed data on 47,617 OVC caregivers who reported their HIV status to the USAID Kizazi Kipya project's CCWs as positive or negative. Caregivers of unknown HIV status or those who did not disclose their HIV status to the project were excluded from the analysis. A caregiver is defined by the project as a guardian who has the greatest responsibility for the daily care and rearing of one or more OVC in a household. A caregiver is not necessarily a biological parent of the OVC in the household.

\section{Variables}

Caregiver HIV status was the outcome or dependent variable for this study. HIV status was self-reported by the caregiver during beneficiary screening and enrollment. An emphasis has been given that in the era of ART, asking respondents to self-report their HIV status is crucial for measuring and improving access to and coverage of HIV treatment and prevention services. ${ }^{24}$ Self-reporting HIV status is also important for estimating the true size of the unmet needs in addressing the HIV epidemic and for correct interpretation of the behaviors associated with the acquisition and transmission of the HIV infection. ${ }^{24}$ For computational purposes, the variable was coded as ' 0 ' if the caregiver was HIV negative and ' 1 ' if the caregiver was HIV positive.

The main independent variable for the current study was food insufficiency which was based on household level of hunger. The construction of the variable was informed by the Household Hunger Scale (HHS) designed by the Food and Agriculture Organization (FAO) and the Tufts University through the Food and Nutrition Technical Assistance III Project (FANTA). ${ }^{25}$ The HHS originates from the Household Food Insecurity Access Scale (HFIAS). ${ }^{25}$ It is a validated scale for cross-cultural use in food insecure areas, thus different from other food security indicators. ${ }^{25}$ According to the HHS, there are three household hunger categories based on household hunger score: (a) little to no hunger, (b) moderate hunger, and (c) severe hunger.

Other independent variables included were: caregiver's sex, age, marital status, level of formal education attained, family size, health insurance, whether the caregiver was physically or mentally disabled, and place of residence.

\section{Data Analysis}

Data analysis began with one-way tabulation of each variable to obtain distributional features of the respondents. Then, cross-tabulations of HIV status by each of the independent variables was conducted. For each pair of variables cross-tabulated, the purpose was to assess how HIV status varied by levels of the independent variables. Since all variables were categorical, chi-squared test was used to assess the significance of association between HIV status and each of the independent variables. Finally, a randomeffects logistic regression model was fitted in the 
multivariate analysis to identify factors associated with HIV status among the caregivers. All the independent variables were adjusted for each other in the multivariate analysis. The random-effects logistic regression model was used to account for clustering of the data. ${ }^{26}$ Caregivers living in geographic proximity were assumed to be correlated. Stata statistical software (version 14.0; StataCorp LP, College Station, TX, USA) was used for all data analyses, and all statistical inferences were made at the significance level of $5 \%(\alpha=0.05)$.

\section{Results}

\section{Profile of Respondents}

The analysis included 47,617 OVC caregivers aged 18 years and above. Their mean age was 50.7 years. The majority of the caregivers were female (73.7\%), resided in rural areas $(65.5 \%)$, and had primary education (76.8\%). In terms of marital status, most of the caregivers were married or living together with their spouses (42.7\%), and widowed (35.2\%) (Table 2).

\section{HIV Infection by Background Characteristics}

As shown in Table 3, overall, 28.3\% $(n=13,464)$ of the caregivers reported that they were HIV positive. This varied by the level of household hunger and became $30.1 \%, 26.8 \%$ and $34.2 \%$ among caregivers from little to no hunger households, moderate hunger households, and severe hunger households, respectively $(p<0.001)$. With respect to sex, $28.0 \%$ and $29.2 \%$ of female and male caregivers were HIV positive, respectively $(p=0.011)$.

In addition, rural residences were associated with higher HIV prevalence than their urban counterparts (32.6\% against $20.1 \%)(p<0.001)$. Regarding marital status, the proportion of HIV-positive caregivers ranged from $23.4 \%$ among those who were married or living together with their spouses to $33.4 \%$ among those who were widowed $(p<0.001)$. HIV prevalence was lowest among the oldest $(60+$ years $)$ caregivers $(16.2 \%)$ and highest among caregivers in the age group 40-49 years (36.7\%) $(p<0.001)$. HIV prevalence was lowest $(21.7 \%)$ among caregivers with secondary or higher education and highest (29.1\%) among caregivers who had primary education $(p<0.001)$. HIV prevalence was higher among caregivers in families with two to three people $(29.6 \%)$ and lowest among those in bigger families of seven or more people $(26.9 \%)(p<0.001)$. Mental or physical
Table 2 Sociodemographic Profile of Respondents $(n=47,617)$

\begin{tabular}{|c|c|c|}
\hline Variable & $\begin{array}{l}\text { Number of } \\
\text { Caregivers (n) }\end{array}$ & $\begin{array}{l}\text { Percent } \\
\text { (\%) }\end{array}$ \\
\hline Overall & 47,617 & 100.0 \\
\hline \multicolumn{3}{|l|}{ Caregiver HIV status } \\
\hline Negative & 34,153 & 71.7 \\
\hline Positive & 13,464 & 28.3 \\
\hline \multicolumn{3}{|l|}{ Household level of hunger } \\
\hline Little to no hunger & 16,014 & 33.6 \\
\hline Moderate hunger & 29,412 & 61.8 \\
\hline Severe hunger & 2191 & 4.6 \\
\hline \multicolumn{3}{|l|}{ Type of residence } \\
\hline Rural & 31,225 & 65.6 \\
\hline Urban & 16,392 & 34.4 \\
\hline \multicolumn{3}{|l|}{ Marital status } \\
\hline Married and living together & 20,321 & 42.7 \\
\hline Married and living apart & 2188 & 4.6 \\
\hline Cohabiting (but not married)/other & $|87|$ & 3.9 \\
\hline Never been married & 2590 & 5.4 \\
\hline Divorced or separated & 3910 & 8.2 \\
\hline Widow/widower & 16,737 & 35.2 \\
\hline \multicolumn{3}{|l|}{ Sex } \\
\hline Female & 35,095 & 73.7 \\
\hline Male & 12,522 & 26.3 \\
\hline \multicolumn{3}{|l|}{ Age group (in years) } \\
\hline $18-29$ & 2153 & 4.5 \\
\hline $30-39$ & 8920 & 18.7 \\
\hline $40-49$ & 13,774 & 28.9 \\
\hline $50-59$ & 9823 & 20.6 \\
\hline $60+$ & 12,947 & 27.2 \\
\hline Mean $=50.7, S D=14.2$ & - & - \\
\hline Median=49.0, $I Q R=21.0$ & & \\
\hline \multicolumn{3}{|l|}{ Education } \\
\hline Never attended & 9461 & 19.9 \\
\hline Primary & 36,544 & 76.8 \\
\hline Secondary+ & 1612 & 3.4 \\
\hline \multicolumn{3}{|l|}{ Family size (number of people } \\
\hline living in a household) & & \\
\hline 2-3 people & $|7,47|$ & 36.7 \\
\hline 4-6 people & 22,054 & 46.3 \\
\hline $7+$ people & 8092 & 17.0 \\
\hline \multicolumn{3}{|l|}{$\begin{array}{l}\text { Is the caregiver mentally or } \\
\text { physically disabled? }\end{array}$} \\
\hline No & 46,022 & 96.7 \\
\hline Yes & 1595 & 3.4 \\
\hline \multicolumn{3}{|l|}{$\begin{array}{l}\text { Household has health } \\
\text { insurance (CHF/TIKA) }\end{array}$} \\
\hline No & 39,351 & 82.6 \\
\hline Yes & 8266 & 17.4 \\
\hline
\end{tabular}


Table 3 Percent of HIV Positive Caregivers by Background Characteristics $(n=47,617)$

\begin{tabular}{|c|c|c|}
\hline & $\begin{array}{l}\text { Percent of } \\
\text { Caregivers who } \\
\text { were HIV Positive }\end{array}$ & p-value* \\
\hline Overall & 28.3 & - \\
\hline $\begin{array}{l}\text { Household level of hunger } \\
\text { Little to no hunger } \\
\text { Moderate hunger } \\
\text { Severe hunger }\end{array}$ & $\begin{array}{l}30.1 \\
26.8 \\
34.2\end{array}$ & $<0.001$ \\
\hline $\begin{array}{l}\text { Type of residence } \\
\text { Rural } \\
\text { Urban }\end{array}$ & $\begin{array}{l}32.6 \\
20.1\end{array}$ & $<0.001$ \\
\hline $\begin{array}{l}\text { Marital status } \\
\text { Married and living together } \\
\text { Married and living apart } \\
\text { Cohabiting (but not married)/other } \\
\text { Never been married } \\
\text { Divorced or separated } \\
\text { Widow/widower }\end{array}$ & $\begin{array}{l}23.4 \\
27.2 \\
26.6 \\
28.7 \\
32.5 \\
33.4\end{array}$ & $<0.001$ \\
\hline $\begin{array}{l}\text { Sex } \\
\text { Female } \\
\text { Male }\end{array}$ & $\begin{array}{l}28.0 \\
29.2\end{array}$ & 0.011 \\
\hline $\begin{array}{l}\text { Age group (in years) } \\
\begin{array}{l}18-29 \\
30-39 \\
40-49 \\
50-59 \\
60+\end{array}\end{array}$ & $\begin{array}{l}19.5 \\
30.5 \\
36.7 \\
32.3 \\
16.2\end{array}$ & $<0.001$ \\
\hline $\begin{array}{l}\text { Education } \\
\text { Never attended } \\
\text { Primary } \\
\text { Secondary+ }\end{array}$ & $\begin{array}{l}26.1 \\
29.1 \\
21.7\end{array}$ & $<0.001$ \\
\hline $\begin{array}{l}\text { Family size (number of people } \\
\text { living in a household) } \\
2-3 \text { people } \\
\text { 4-6 people } \\
7+\text { people }\end{array}$ & $\begin{array}{l}29.6 \\
27.8 \\
26.9\end{array}$ & $<0.001$ \\
\hline $\begin{array}{l}\text { Is the caregiver mentally or } \\
\text { physically disabled? } \\
\text { No } \\
\text { Yes }\end{array}$ & $\begin{array}{l}28.4 \\
25.0\end{array}$ & 0.003 \\
\hline $\begin{array}{l}\text { Household has health } \\
\text { insurance (CHF/TIKA) } \\
\text { No } \\
\text { Yes }\end{array}$ & $\begin{array}{l}27.7 \\
31.3\end{array}$ & $<0.001$ \\
\hline
\end{tabular}

Notes: *p-values are based on chi-squared test. Of the 47,617 OVC caregivers analyzed, $28.3 \%(n=13,464)$ of them were HIV positive and the rest $71.7 \%$ ( $n=34,153)$ were HIV negative. Therefore, only those who were HIV positive are presented here, with an implied presence of the HIV negative category. To compare them across the background characteristics, row percent option was used. disability was associated with lower HIV prevalence than lack of it $(25.0 \%$ against $28.4 \%) \quad(p=0.003)$. Ownership of health insurance was associated with higher HIV prevalence than lack of it $(31.3 \%$ against $27.7 \%)(p<0.001)$.

\section{Results from Multivariate Analysis}

Table 4 presents adjusted ORs and their corresponding 95\% CIs of the factors associated with caregiver HIV infection for all the models. There are three models: an overall model for all the caregivers $(n=47,617)$, and two models in the stratified analysis - one for female caregivers $(n=35,095)$ and another one for male caregivers $(n=12,522)$.

In the overall model, caregivers from moderate hunger households were significantly $10 \%$ more likely to be HIV positive than those from little to no hunger households $(\mathrm{OR}=1.10,95 \% \mathrm{CI}: 1.03-1.18)$. This likelihood increased to $51 \%$ among caregivers from severe hunger households than little to no hunger ones $(\mathrm{OR}=1.51,95 \% \mathrm{CI}$ : $1.32-$ 1.74). In the stratified analysis, these observations were significant for female caregivers (moderate hunger households: $\mathrm{OR}=1.09,95 \% \mathrm{CI}: 1.02-1.18$; sever hunger households: $\mathrm{OR}=1.58,95 \% \mathrm{CI}: 1.35-1.84$ ).

Caregivers living in urban areas were 55\% less likely to be living with HIV than their rural counterparts $(\mathrm{OR}=0.45,95 \% \mathrm{CI}: 0.40-0.51)$. This was $51 \%(\mathrm{OR}=0.49$, 95\%CI: $0.43-0.55)$ and $67 \%(\mathrm{OR}=0.33,95 \% \mathrm{CI}: 0.27-$ 0.40 ) among female and male caregivers, respectively.

Marital status was also significantly associated with HIV infection among all the caregivers, as well as among female and male caregivers. In the overall model, caregivers in all other marital categories were significantly more likely to be HIV positive than those who were married or living together with their spouses $(p<0.05)$. This trend was the same among female caregivers $(p<0.001)$. However, there was a slight difference for male caregivers, whereby, only male caregivers who were divorced/separated $(p<0.001)$, and widowed $(p<0.001)$ were significantly more likely to be HIV positive than male caregivers who were married or living together with spouses.

Male caregivers were significantly $18 \%$ more likely than their female counterparts to be HIV positive $(\mathrm{OR}=1.18,95 \% \mathrm{CI}: 1.11-1.26)$. With respect to age, caregivers in the age groups $30-39$ years $(\mathrm{OR}=1.73,95 \% \mathrm{CI}$ : 1.51-1.99), 40-49 years $(\mathrm{OR}=2.17,95 \% \mathrm{CI}: 1.90-2.49)$, and $50-59$ years $(\mathrm{OR}=1.64,95 \% \mathrm{CI}: 1.42-1.88)$ were sig- 
Table 4 Random-effects Logistic Regression of Factors Associated with HIV Infection Among Caregivers of OVC in Tanzania $(n=47,617)$

\begin{tabular}{|c|c|c|c|c|c|c|c|c|c|}
\hline \multirow[t]{3}{*}{ Covariates } & \multicolumn{3}{|c|}{ All Caregivers $(n=47,617)$} & \multicolumn{3}{|c|}{$\begin{array}{l}\text { Female Caregivers } \\
(n=35,095)\end{array}$} & \multicolumn{3}{|c|}{ Male Caregivers $(n=\mid 2,522)$} \\
\hline & \multirow[t]{2}{*}{ OR } & \multicolumn{2}{|l|}{$95 \% \mathrm{Cl}$} & \multirow[t]{2}{*}{ OR } & \multicolumn{2}{|l|}{$95 \% \mathrm{Cl}$} & \multirow[t]{2}{*}{ OR } & \multicolumn{2}{|l|}{$95 \% \mathrm{Cl}$} \\
\hline & & $\begin{array}{l}\text { Lower } \\
\text { Limit }\end{array}$ & $\begin{array}{l}\text { Upper } \\
\text { Limit }\end{array}$ & & $\begin{array}{l}\text { Lower } \\
\text { Limit }\end{array}$ & $\begin{array}{l}\text { Upper } \\
\text { Limit }\end{array}$ & & $\begin{array}{l}\text { Lower } \\
\text { Limit }\end{array}$ & $\begin{array}{l}\text { Upper } \\
\text { Limit }\end{array}$ \\
\hline \multicolumn{10}{|l|}{ Household level of hunger } \\
\hline Little to no hunger & 1.00 & - & - & 1.00 & - & - & 1.00 & - & - \\
\hline Moderate hunger & $* * 1.10$ & 1.03 & 1.18 & $* * 1.09$ & 1.02 & 1.18 & 0.98 & 0.86 & I.II \\
\hline Severe hunger & $* * *|.5|$ & 1.32 & 1.74 & $* * * 1.58$ & 1.35 & 1.84 & 1.12 & 0.84 & 1.49 \\
\hline \multicolumn{10}{|l|}{ Type of residence } \\
\hline Rural & 1.00 & - & - & 1.00 & - & - & 1.00 & - & - \\
\hline Urban & $* * * 0.45$ & 0.40 & 0.51 & $* * * 0.49$ & 0.43 & 0.55 & $* * * 0.33$ & 0.27 & 0.40 \\
\hline \multicolumn{10}{|l|}{ Marital status } \\
\hline Married and living together & 1.00 & - & - & 1.00 & - & - & 1.00 & - & - \\
\hline Married and living apart & $* * 1.20$ & 1.07 & 1.36 & $* * * 1.33$ & 1.15 & 1.54 & 1.09 & 0.85 & 1.39 \\
\hline Cohabiting (but not married)/other & $* * * 1.39$ & 1.22 & 1.59 & $* * * 1.60$ & 1.38 & 1.86 & 1.01 & 0.74 & 1.39 \\
\hline Never been married & $* * * 1.63$ & 1.45 & 1.83 & $* * * 1.81$ & 1.60 & 2.05 & 1.02 & 0.72 & 1.45 \\
\hline Divorced or separated & $* * * 1.64$ & 1.49 & 1.80 & $* * *|.8|$ & 1.62 & 2.01 & $* * * 1.56$ & 1.23 & 1.99 \\
\hline Widow/widower & $* * * 2.03$ & 1.91 & 2.16 & $* * * 2.30$ & 2.14 & 2.48 & $* * * 1.61$ & 1.40 & 1.85 \\
\hline \multicolumn{10}{|l|}{ Sex } \\
\hline Female & 1.00 & - & - & - & - & - & - & - & - \\
\hline Male & $* * * 1.18$ & 1.11 & 1.26 & - & - & - & - & - & - \\
\hline Age group (in years) & & & & - & - & - & - & - & - \\
\hline $18-29$ & 1.00 & - & - & 1.00 & - & - & 1.00 & - & - \\
\hline $30-39$ & $* * * 1.73$ & 1.51 & 1.99 & $* * * 1.70$ & 1.46 & 1.98 & $* * * 1.87$ & 1.33 & 2.64 \\
\hline $40-49$ & $* * * 2.17$ & 1.90 & 2.49 & $* * * 2.10$ & 1.81 & 2.43 & $* * * 2.61$ & 1.87 & 3.65 \\
\hline $50-59$ & $* * * 1.64$ & 1.42 & 1.88 & $* * * 1.46$ & 1.25 & 1.70 & $* * * 2.36$ & 1.69 & 3.31 \\
\hline $60+$ & $* * * 0.57$ & 0.49 & 0.66 & $* * * 0.49$ & 0.42 & 0.58 & 0.77 & 0.55 & 1.08 \\
\hline \multicolumn{10}{|l|}{ Education } \\
\hline Never attended & 1.00 & - & - & 1.00 & - & - & 1.00 & - & - \\
\hline Primary & $* * * 1.28$ & 1.19 & 1.37 & $* * * \mid .21$ & 1.12 & 1.31 & $* * * 1.36$ & 1.17 & 1.58 \\
\hline Secondary+ & 1.08 & 0.92 & 1.26 & 1.12 & 0.93 & 1.35 & 0.87 & 0.64 & 1.19 \\
\hline \multicolumn{10}{|l|}{$\begin{array}{l}\text { Family size (number of people living } \\
\text { in a household) }\end{array}$} \\
\hline 2-3 people & 1.00 & - & - & 1.00 & - & - & 1.00 & - & - \\
\hline 4-6 people & $* * 0.92$ & 0.87 & 0.97 & $* * * 0.87$ & 0.81 & 0.93 & 1.09 & 0.97 & 1.22 \\
\hline 7+ people & $* * * 0.76$ & 0.71 & 0.83 & $* * 0.71$ & 0.65 & 0.78 & 0.97 & 0.83 & 1.14 \\
\hline \multicolumn{10}{|l|}{$\begin{array}{l}\text { Is the caregiver mentally or physically } \\
\text { disabled? }\end{array}$} \\
\hline No & 1.00 & - & - & 1.00 & - & - & 1.00 & - & - \\
\hline Yes & $* * 0.85$ & 0.74 & 0.97 & 0.89 & 0.75 & 1.06 & $* * 0.71$ & 0.55 & 0.91 \\
\hline \multicolumn{10}{|l|}{$\begin{array}{l}\text { Household has health insurance } \\
\text { (CHF/TIKA) }\end{array}$} \\
\hline No & 1.00 & - & - & 1.00 & - & - & 1.00 & - & - \\
\hline Yes & $* * 1.08$ & 1.002 & 1.16 & $* * 1.12$ & 1.03 & 1.22 & 0.94 & 0.82 & 1.08 \\
\hline
\end{tabular}


Table 4 (Continued).

\begin{tabular}{|c|c|c|c|c|c|c|c|c|c|}
\hline \multirow[t]{3}{*}{ Covariates } & \multicolumn{3}{|c|}{ All Caregivers $(n=47,617)$} & \multicolumn{3}{|c|}{$\begin{array}{l}\text { Female Caregivers } \\
(n=35,095)\end{array}$} & \multicolumn{3}{|c|}{ Male Caregivers $(n=\mid 2,522)$} \\
\hline & \multirow[t]{2}{*}{ OR } & \multicolumn{2}{|l|}{$95 \% \mathrm{Cl}$} & \multirow[t]{2}{*}{ OR } & \multicolumn{2}{|l|}{$95 \% \mathrm{Cl}$} & \multirow[t]{2}{*}{ OR } & \multicolumn{2}{|l|}{$95 \% \mathrm{Cl}$} \\
\hline & & $\begin{array}{l}\text { Lower } \\
\text { Limit }\end{array}$ & $\begin{array}{l}\text { Upper } \\
\text { Limit }\end{array}$ & & $\begin{array}{l}\text { Lower } \\
\text { Limit }\end{array}$ & $\begin{array}{l}\text { Upper } \\
\text { Limit }\end{array}$ & & $\begin{array}{l}\text { Lower } \\
\text { Limit }\end{array}$ & $\begin{array}{l}\text { Upper } \\
\text { Limit }\end{array}$ \\
\hline Constant & $* * * 0.18$ & 0.15 & 0.21 & $* * * 0.19$ & 0.15 & 0.22 & $* * * 0.18$ & 0.12 & 0.24 \\
\hline Model Statistics & \multicolumn{3}{|c|}{$\begin{array}{l}* * * p<0.00 I, * * p<0.05 ; \text { rho } \\
(I C C)=0.37 ; \text { number of } \\
\text { villages }=3242, \min =1, \\
\text { average }=14.7, \max =253 ; \\
\text { integration points }=100\end{array}$} & \multicolumn{3}{|c|}{$\begin{array}{l}* * * p<0.00 I, * * p<0.05 ; \text { rho } \\
(I C C)=0.34 ; \text { number of } \\
\text { villages }=308 I, \min =I, \\
\text { average }=11.4, \max =213 ; \\
\text { integration points }=100\end{array}$} & \multicolumn{3}{|c|}{$\begin{array}{l}* * * p<0.00 I, * * p<0.05 ; \text { rho } \\
(I C C)=0.41 ; \text { number of } \\
\text { villages }=2356, \min =1, \\
\text { average }=5.3, \max =90 ; \\
\text { integration points }=100\end{array}$} \\
\hline
\end{tabular}

nificantly more likely than those in the youngest age group (18-29 years) to be HIV positive. However, caregivers in the oldest age group (60+ years) were significantly $43 \%$ less likely to be HIV positive than the youngest caregivers $(\mathrm{OR}=0.57$, 95\%CI: 0.49-0.66). This trend was the same for female caregivers, but slightly different for male caregivers. The slight difference was that the oldest male caregivers were statistically similar with the youngest caregivers in terms of their likelihood of being HIV positive $(p>0.05)$.

Caregivers with primary education were 28\% more likely than those who had never been to school to be HIV positive (OR=1.28, 95\%CI: 1.19-1.37). Those who had secondary education or higher were statistically not different from those who had never been to school $(p>0.05)$. This trend did not change for female or male caregivers.

The likelihood of HIV infection declined as the family size increased. Caregivers living in families of four to six people were $8 \%$ less likely than those in smallest families (two to three people) to be HIV positive $(\mathrm{OR}=0.92,95 \% \mathrm{CI}$ : 0.87-0.97). Caregivers living in families with seven or more people were $24 \%$ less likely than those in smallest families to be HIV positive $(\mathrm{OR}=0.76$, 95\%CI: $0.71-0.83)$. This trend was the same for female caregivers. However, family size had no significant association with HIV infection among male caregivers $(p>0.05)$.

Caregivers who were mentally or physically disabled were $15 \%$ less likely to be HIV positive than those who were not disabled $(\mathrm{OR}=0.85,95 \% \mathrm{CI}: 0.74-0.97)$. This trend was the same for male caregivers $(\mathrm{OR}=0.71,95 \%$ CI: 0.55-0.91). However, disability status had no significant association with HIV infection among female caregivers $(p>0.05)$.

Having health insurance was significantly associated with HIV infection overall $(\mathrm{OR}=1.08$, 95\%CI: $1.002--$ 1.16), and among female caregivers $(\mathrm{OR}=1.12$, 95\% $\mathrm{CI}$ : 1.03-1.22); but the association disappeared among male caregivers $(p>0.05)$.

\section{Discussion}

This study assessed how food insufficiency and other individual and household factors relate to HIV infection among caregivers of OVC in Tanzania. Results showed that out of the 47,617 caregivers analyzed, $28.3 \%$ were living with HIV (28.0\% in female and $29.2 \%$ in male caregivers). This proportion was much higher than the national estimate of $4.9 \%$ among the general adult population aged 15 years and older. ${ }^{27}$ Like key and vulnerable populations, ${ }^{9-11}$ this observation suggested that caregivers of OVC are at a higher risk of HIV acquisition than the general population, thus there is a need for more targeted HIV testing and treatment interventions for them.

In the multivariate analysis, the caregiver's likelihood of being HIV positive increased with food insufficiency. In the stratified analysis, the effect was significant for female caregivers. This finding is consistent with several others. $^{28-30}$ One of the possible mechanisms responsible for food insufficiency is that while concentrating on taking care of the OVC, the caregiver may not always have adequate time to participate in food production activities such as farming or income generating businesses. ${ }^{31}$ Since lack of adequate food increases HIV risk behaviors, ${ }^{32}$ the likelihood of HIV infection increases as well. The literature further shows that food insufficiency and HIV are 
intertwined in a vicious circle that increases the vulnerability of each condition. ${ }^{33}$ Food insufficiency leads to malnutrition, a condition that compromises body immunity and consequently increases the risk of HIV acquisition. ${ }^{34}$ Moreover, HIV/AIDS can intensify food insecurity by weakening the most productive household members, thus poor household economic capacity and increased caregiver burden. $^{35,36}$ This suggests that food sufficiency can be considered an imperative criterion for targeted HIV testing services to enhance progress in the first 90 of the UNAIDS' $90-90-90$ targets. $^{37}$ The finding also reemphasizes the need to integrate food security interventions in HIV/AIDS programming to improve the health and quality of life among PLHIV.

This study also observed several other factors with significant association with HIV infection among the caregivers. With respect to sex, male caregivers were $18 \%$ more likely than their female counterparts to be living with HIV. This is contrary to the usual trend in the general population, where women are disproportionally infected

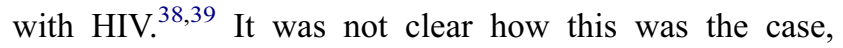
thus a need for further research to understand the underlying linkages between the two. Male caregivers may need additional HIV counselling, testing, and treatment support for their better health and social outcomes.

Caregivers living in urban areas were significantly $55 \%$ less likely to be living with HIV than their rural counterparts. This trend was unaltered in the subgroup of female and male caregivers. Due to migration between rural and urban areas, the HIV epidemic is no longer an urban phenomenon as it was initially thought to be. ${ }^{40}$ This observation is consistent with one study in Tanzania that found higher HIV prevalence in the rural than in the urban adult population. $^{41}$ However, another study on socioeconomic status and HIV seroprevalence in Tanzania did not find a significant association between the type of residence and HIV seropositivity. ${ }^{42}$ Similarly, Adebayo et al did not find a significant variation in HIV prevalence between rural and urban settings in Nigeria. ${ }^{43}$ However, studies showing higher likelihood of HIV infection in urban than in rural areas exist. ${ }^{4-46}$ Further research may help to clarify the observed association.

In terms of marital status, caregivers in all other marital categories were significantly more likely to be living with HIV than those who were currently married and living together with their spouses. Similarly, in the sex-stratified analyses, being in a marital union was also a protective factor among both male and female caregivers. This observation was largely consistent with others in the literature. $^{43,47-50}$ A qualitative study from Uganda argues that staying together in marriage may be about being faithful, ${ }^{47}$ an act which not only sustains the marriage, but also reduces the risk of HIV infection to the spouses. The study further pointed out that perceived socioeconomic and cultural benefits of marriage such as having children, property acquisition, and social status, tend to outshine the cost of infidelity that includes the risk of HIV acquisition. ${ }^{47}$ This is an important dimension for HIV risk aversion. In Malawi, one study showed that marriages can be used as union-based HIV risk avoidance. ${ }^{48}$ Another study in Nigeria found lower HIV prevalence among married women than formerly married women and concluded that matrimony plays a huge role in hindering the spread of HIV. ${ }^{49}$ This implies that outside marital union, women lack the socioeconomic and cultural benefits of marriage, and in turn, they may become involved in sex work or intergenerational relationships for economic gain. ${ }^{50}$ In this case, they lose their ability to negotiate safer sex practices, therefore, they are greatly exposed to the risk of HIV infection. This study was unable to establish why divorcees and widowed men were at higher likelihood of being HIV positive than the rest of the men in other marital categories, thus a need for further research. Therefore, caregivers outside marital unions can be targeted with HIV testing and treatment services to curtail the HIV epidemic.

There was a significant association between age and HIV infection among the caregivers. Caregivers in the age groups 30-39, 40-49, and 50-59 years were more likely to be living with HIV than those who were in the age group 18-29 years. Those in the oldest age group (60+ years) were less likely to be living with HIV than those who were in the youngest age group (18-29 years). It is possible that caregivers in the middle age groups were more sexually active, thus more exposed to the risks of HIV infection than the youngest and the oldest caregivers. The HIV prevalence declined among caregivers in the oldest age groups possibly because some of them had died. A study in South India found that HIV seropositivity was associated with age $\geq 31$ years. ${ }^{51}$ However, this study was unable to establish at which age the respondent acquired the HIV infection. This suggests a need for further research such as cohort studies to precisely estimate the timing of infection occurrence to reveal age groups that require targeted efforts for prevention and treatment services. 
Regardless of their sex, caregivers with primary education were significantly $28 \%$ more likely to be living with HIV than those who had never been to school. However, caregivers with secondary or higher education were not statistically different $(p>0.05)$ from those who had never been to school to be living with HIV. Although education attainment allows people to have clear perspectives about life issues including disease prevention, ${ }^{52}$ in the literature, there are studies which have established a relationship between lower education and higher likelihood of HIV seropositivity, ${ }^{52-55}$ while others found higher HIV infection with higher education. ${ }^{43,56-58}$ Such conflicting evidence suggests a need for further research to establish clarity. Several theories such as the social cognitive theory can be an instrumental basis for describing behavioral issues of human beings. They identify a set of core determinants and a mechanism through which they work, including the issue of knowledge about the health risks associated with certain behaviours and how a person translates such knowledge into safe behaviours. While knowledge of health risks and benefits creates the precondition for change, this may not always be the case. ${ }^{59}$

This study observed further that the bigger the family size the lower the likelihood that the caregiver was HIV positive. This was also the case among female caregivers, but the significance disappeared in male caregivers. It was not immediately clear whether caregivers with bigger families (4+ people) had a high level of family and social support, thus less exposure to HIV risks. One study in Tanzania on the relationship between living arrangements and HIV risk, observed that living alone increased the odds of being HIV positive among key and vulnerable populations and the general population. ${ }^{60}$ However, this observation remains rare in the literature, thus a need for more studies to clarify the mechanism underlying this finding.

Living with mental or physical disability was significantly associated with a $16 \%$ lower likelihood of HIV infection among all the caregivers. In the stratified analysis, this effect was 30\% among male caregivers. Disability status was not significantly associated with HIV infection among female caregivers $(p>0.05)$. This could be that since over $80 \%$ of HIV infection in developing countries occur sexually, ${ }^{6,7}$ those (especially male caregivers) who are physically or mentally challenged may not be as sexually active as those who are not, thus less risk of HIV acquisition among them.

Caregivers with health insurance were significantly $8 \%$ more likely to be living with HIV than those without. This effect was significantly $13 \%$ higher among female caregivers. Health insurance ownership had no significant association with HIV infection among male caregivers $(p>0.05)$. Note that about three quarters of the caregivers were female. The caregivers analyzed in the current study were receiving support from another project called Pamoja Tuwalee (PT) before enrolling into the USAID Kizazi Kipya project. The PT project facilitated acquisition of health insurance for the poorest households among other services. The poorest households were also food insufficient, thus more likely to have HIV positive caregivers as already observed.

\section{Strengths and Limitations}

This study is based on a large sample of OVC caregivers $(n=47,617)$ and uses robust and advanced statistical methods to process the data, thus yielding strong and statistically reliable results which can be relied upon to target HIV testing and treatment services to curb the HIV epidemic in the population.

However, data for this was self-reported by the respective caregiver, and there was no means for objective verification of the answers. Since self-reports are subject to recall bias, the project screening and enrollment team conducted further probes to confirm responses where possible before recoding their responses. This study is unlikely to establish causality of its findings because cross-sectional studies lack temporality. Moreover, generalization of the findings beyond Tanzania may be unlikely.

\section{Conclusion}

The current study reveals that OVC caregivers who are moderately or severely food insufficient are more likely to be HIV positive than those who are not, suggesting that improving access to adequate food has a potential to reduce HIV risks among the caregivers.

In addition, the likelihood of HIV infection among the caregivers is higher in rural areas; those in age groups $30-39,40-49$, and $50-59$ years, as well as in those with primary education, and smaller family sizes (two to three people). Similarly, outside marital union, the likelihood of HIV infection among caregivers is higher.

These factors are very important as they reveal different segments of the caregiver population at higher risk of HIV infection that can be targeted with additional HIV testing and treatment support toward ending the HIV epidemic. 


\section{Data Sharing Statement}

The datasets analyzed during the current study are not publicly available due to the risk of identifying participants who are the beneficiaries of the USAID Kizazi Kipya project, but are available from the corresponding author on reasonable request.

\section{Ethics Approval}

Ethics approval was received from the Medical Research Coordinating Committee (MRCC) of the National Institute for Medical Research (NIMR) in Tanzania (NIMR/HQ/R.8a/ Vol.IX/3024). Screening and enrollment of beneficiaries into the USAID Kizazi Kipya project was voluntary. Each participant signed a statement of an informed consent form before completing the FCAA tool. Storage of the project data is very secure and confidential, with access limited to a few staff.

\section{Acknowledgments}

An earlier version of this manuscript was presented as an electronic poster at the 6th Tanzania Health Summit (THS) that took place at the Dodoma Convention Centre in Dodoma, Tanzania, 27-28 November 2019. Comments received are greatly appreciated. We acknowledge the project staff, the consortium partners implementing the USAID Kizazi Kipya Project, Civil Society Organizations (CSOs), Community Case Workers (CCW) and District Social Welfare Officers (DSWO).

\section{Disclosure}

The authors declare that they have no conflicting interests.

\section{References}

1. UNAIDS. United Republic of Tanzania. UNAIDS; 2018. Available from: https://www.unaids.org/en/regionscountries/countries/unitedrepu blicoftanzania. Accessed Oct 10, 2019.

2. Tanzania Commission for AIDS (TACAIDS). National bureau of statistics (NBS), ORC macro. Tanzania HIV/AIDS Indicator Survey 2003-04. Calverton, Maryland, USA: TACAIDS, NBS, and ORC Macro; 2005. Available from: https://dhsprogram.com/pubs/pdf/AIS1/ 00FrontMatter.pdf\#[1,\{\%22name\%22:\%22FitH $\% 22\}, 793$.]. Accessed Feb 1, 2019.

3. Tanzania Commission for AIDS (TACAIDS), Zanzibar AIDS Commission (ZAC). Tanzania HIV Impact Survey (THIS) 2016-2017: final Report. Dar es Salaam, Tanzania; 2018. Available from: http://www.nbs.go.tz/nbs/takwimu/this2016-17/Tanzania_ SummarySheet_English.pdf. Accessed Sep 18, 2018.

4. International Partnership for Microbicides. HIV/AIDS: a global epidemic; 2010. Available from: https://www.ipmglobal.org/whymicrobicides/hiv/aids-global-epidemic. Accessed Jan 31, 2018.

5. UNAIDS. Ending AIDS: progress towards the 90- 90-90Targets. Geneva, Switzerland: UNAIDS; 2017. Available from: http://www. unaids.org/sites/default/files/media_asset/Global_AIDS_update_2017_ en.pdf. Accessed July 8, 2020.
6. National AIDS Control Programme (NACP). National Guidelines for the Management of HIV and AIDS. Dar es Salaam, Tanzania; 2015.

7. UNAIDS. Estimating national adult prevalence of HIV-1 in generalized epidemics. UNAIDS, WHO; 2007. Available from: http://data. unaids.org/pub/manual/2007/epp_genepi_2007_en.pdf. Accessed July 8,2020 .

8. Mayer KH, Beyrer C. HIV epidemiology update and transmission factors: risks and risk contexts - 16th international AIDS conference epidemiology plenary. Clin Infect Dis. 2007;44(7):981-987. doi: $10.1086 / 512371$

9. Williams ML, McCurdy SA, Bowen AM, et al. HIV seroprevalence in a sample of Tanzanian intravenous drug users. AIDS Educ Prev. 2009;21(5):474-483. doi:10.1521/aeap.2009.21.5.474

10. National AIDS Control Programme (Tanzania). The Cost of Comprehensive HIV Treatment in Tanzania: Report of a Cost Study of HIV Treatment Programs in Tanzania. Dar Es Salaam: The United Republic of Tanzania. Ministry of Health and Social Welfare, National AIDS Control Programme; 2011.

11. Ross MW, Nyoni J, Ahaneku HO, Mbwambo J, McClelland RS, McCurdy SA. High HIV seroprevalence, rectal STIs and risky sexual behaviour in men who have sex with men in Dar es Salaam and Tanga, Tanzania. BMJ Open. 2014;4(8):e006175-e006175. doi:10.1136/bmjopen-2014-006175

12. Croce F, Fedeli P, Dahoma M, et al. Risk factors for HIV/AIDS in a low HIV prevalence site of sub-Saharan Africa. Trop Med Int Health. 2007;12(9):1011-1017. doi:10.1111/j.1365-3156.2007. 01880.x

13. Mmbaga EJ, Hussain A, Leyna GH, Mnyika KS, Sam NE, Klepp K-I. Prevalence and risk factors for HIV-1 infection in rural Kilimanjaro region of Tanzania: implications for prevention and treatment. BMC Public Health. 2007;7(1). doi:10.1186/1471-2458-7-58

14. Kapiga SH, Shao JF, Lwihula GK, Hunter DJ. Risk factors for HIV infection among women in Dar-es-Salaam, Tanzania. J Acquir Immune Defic Syndr. 1994;7(3):301-309.

15. El-Bassel N, Shaw SA, Dasgupta A, Strathdee SA. Drug use as a driver of HIV risks: re-emerging and emerging issues. Curr Opin HIV AIDS. 2014;9(2):150-155. doi:10.1097/COH.000000000000 0035

16. Wamoyi J, Stobeanau K, Bobrova N, Abramsky T, Watts C. Transactional sex and risk for HIV infection in sub-Saharan Africa: a systematic review and meta-analysis. J Int AIDS Soc. 2016;19 (1):20992. doi:10.7448/IAS.19.1.20992

17. Choudhry V, Ambresin A-E, Nyakato VN, Agardh A. Transactional sex and HIV risks - evidence from a cross-sectional national survey among young people in Uganda. Glob Health Action. 2015;8 (1):27249. doi:10.3402/gha.v8.27249

18. Tyler KA, Handema R, Schmitz RM, Phiri F, Wood C, Olson K. Risk factors for HIV among Zambian Street youth. J HIV AIDS Soc Serv. 2016;15(3):254-268. doi:10.1080/15381501.2016.1138178

19. Maharaj P. Aging and Health in Africa. Springer Science \& Business Media; 2012.

20. Karimli L, Ssewamala FM, Ismayilova L. Extended families and perceived caregiver support to AIDS orphans in Rakai district of Uganda. Child Youth Serv Rev. 2012;34(7):1351-1358. doi:10.1016/ j.childyouth.2012.03.015

21. CARE. Promising practices: promoting early childhood development for OVC in resource constrained settings: the $5 \times 5$ model. Geneva: care, USAID, hope for african children initiative; 2006. Available from: http://www.crin.org/en/docs/promisingpractices.pdf. Accessed Jun 28, 2018.

22. Schmid GP, Williams BG, Garcia-Calleja JM, et al. The unexplored story of HIV and ageing. Bull World Health Organ. 2009;87(3):162162A. doi:10.2471/BLT.09.064030

23. Pact. Kizazi Kipya: new generation. Pact; 2019. Available from: http://www.pactworld.org/country/tanzania/project. Accessed Aug 20, 2018. 
24. Johnston LG, Sabin ML, Prybylski D, et al. The importance of assessing self-reported HIV status in bio-behavioural surveys. Bull World Health Organ. 2016;94(8):605-612. doi:10.2471/BLT.15.162933

25. Ballard T, Coates J, Swindale A, Deitchler M Household hunger scale: indicator definition and measurement guide. Washington, DC: Food and Nutrition Technical Assistance II Project, FHI 360; 2011. Available from: https://www.fantaproject.org/sites/default/files/resources/HHSIndicator-Guide-Aug2011.pdf. Accessed July 8, 2020.

26. Rodriguez G, Elo I. Intra-class correlation in random-effects models for binary data. Stata J. 2003;3(1):32-46. doi:10.1177/1536867X03 00300102

27. Ministry of Health, Community Development, Gender, Elderly and Children, Tanzania, Ministry of Health, Zanzibar, Tanzania. Tanzania HIV impact survey (THIS) 2016-2017. Dar es Salaam, Tanzania; 2018. Available from: http://library.tacaids.go.tz/bitstream/handle/ 123456789/135/THIS\%202016\%202017_Final\%20Report_1.08. 19 TS-1.pdf?sequence=1\&isAllowed=y. Accessed Jun 20, 2019.

28. Nyirenda M, Street R, Reddy T, et al. Food insecurity, HIV status and prior testing at South African primary healthcare clinics. S Afr J Sci. 2018;114:9/10. doi:10.17159/sajs.2018/4407

29. Adimora AA, Schoenbach VJ, Martinson FEA, et al. Heterosexually transmitted HIV infection among African Americans in North Carolina. J Acquir Immune Defic Syndr. 2006;41(5):616-623. doi:10.1097/01.qai.0000191382.62070.a5

30. Anema A, Vogenthaler N, Frongillo EA, Kadiyala S, Weiser SD. Food insecurity and HIV/AIDS: current knowledge, gaps, and research priorities. Curr HIV/AIDS Rep. 2009;6(4):224-231. doi:10.1007/s11904-009-0030-z

31. Osafo J, Knizek BL, Mugisha J, Kinyanda E. The experiences of caregivers of children living with HIV and AIDS in Uganda: a qualitative study. Glob Health. 2017;13(1):72. doi:10.1186/s12992-017-0294-9

32. Rollins N. Food insecurity - a risk factor for HIV infection. PLoS Med. 2007;4(10):e301. doi:10.1371/journal.pmed.0040301

33. WHO. Nutrient requirements for people living with HIV/AIDS: report of a technical consultation, World Health Organization, Geneva, 13-15 May 2003. Geneva: World Health Organization; 2003. Available from: http://whqlibdoc.who.int/publications/2003/ 9241591196.pdf. Accessed Oct 16, 2019.

34. Gillespie S, Kadiyala S. HIV/AIDS and food and nutrition security: from evidence to action. Int Food Policy Res Inst. 2005.

35. de Waal A, Whiteside A. New variant famine: AIDS and food crisis in southern Africa. Lancetl. 2003;362(9391):1234-1237. doi:10.10 16/S0140-6736(03)14548-5

36. Bukusuba J, Kikafunda JK, Whitehead RG. Food security status in households of people living with HIV/AIDS (PLWHA) in a Ugandan urban setting. $\mathrm{Br} J$ Nutr. 2007;98(1):211-217. doi:10.1017/ S0007114507691806

37. UNAIDS. 90-90-90treatment target; 2018. Available from: https:// www.unaids.org/en/90-90-90. Accessed Jul 22, 2019.

38. Sia D, Onadja Y, Hajizadeh M, Heymann SJ, Brewer TF, Nandi A. What explains gender inequalities in HIV/AIDS prevalence in sub-Saharan Africa? Evidence from the demographic and health surveys. $B M C$ Public Health. 2016;16(1):1136. doi:10.1186/s12889-016-3783-5

39. Magadi MA. Understanding the gender disparity in HIV infection across countries in sub-Saharan Africa: evidence from the demographic and health surveys. Sociol Health Illn. 2011;33(4):522-539. doi:10.1111/j.1467-9566.2010.01304.x

40. Sambisa W, Stokes CS. Rural/urban residence, migration, HIV/AIDS, and safe sex practices among men in Zimbabwe*. Rural Sociol. 2006;71(2):183-211. doi:10.1526/003601106777789684

41. Nyigo V, Kilale A, Kilima S, et al. Magnitude of HIV infection among older people in Mufindi and Babati districts of the Tanzania mainland. HIV AIDS (Auckl). 2014;6:75-79.

42. Msisha W, Kapiga S, Earls F, Subramanian S. Socioeconomic status and HIV seroprevalence in Tanzania: a counterintuitive relationship. Int J Epidemiol. 2008;37(6):1297-1303. doi:10.1093/ije/dyn186
43. Adebayo SB, Olukolade RI, Idogho O, Anyanti J, Ankomah A. Marital status and HIV prevalence in Nigeria: implications for effective prevention programmes for women. Adv Infect Dis. 2013;03 (03):210-218. doi:10.4236/aid.2013.33031

44. Asiedu C, Asiedu E, Owusu F. The socio-economic determinants of HIV/AIDS infection rates in Lesotho, Malawi, Swaziland and Zimbabwe. Dev Policy Rev. 2012;30(3):305-326. doi:10.1111/ j.1467-7679.2012.00578.x

45. Magadi MA. The disproportionate high risk of HIV infection among the urban poor in Sub-Saharan Africa. AIDS Behav. 2013;17 (5):1645-1654. doi:10.1007/s10461-012-0217-y

46. Arroyo M, Hoelscher M, Sateren W, et al. HIV-1 diversity and prevalence differ between urban and rural areas in the Mbeya region of Tanzania. Aids. 2005;19(14):1517-1524. doi:10.1097/01. aids.0000183515.14642.76

47. Agol D, Bukenya D, Seeley J, Kabunga E, Katahoire A. Marriage, intimacy and risk of HIV infection in South West Uganda. Afr $J$ Reprod Health. 2014;18(4):86-94.

48. Reniers G. Marital strategies for regulating exposure to HIV. Demography. 2008;45(2):417-438. doi:10.1353/dem.0.0002

49. Fagbamigbe AF, Adebayo SB, Idemudia E. Marital status and HIV prevalence among women in Nigeria: ingredients for evidence-based programming. Int $J$ Infect Dis. 2016;48:57-63. doi:10.1016/j. ijid.2016.05.002

50. Dunkle KL, Jewkes RK, Brown HC, Gray GE, McIntryre JA, Harlow SD. Transactional sex among women in Soweto, South Africa: prevalence, risk factors and association with HIV infection. Soc Sci Med. 2004;59:1581-1592.

51. Ramachandran R, Chandrasekaran V, Muniyandi M, Jaggarajamma K, Bagchi A, Sahu S. Prevalence and risk factors of HIV infection among clients attending ICTCs in six districts of Tamilnadu, South India. AIDS Res Treat. 2011;2011:650321.

52. Ibrahim SA, Sabitu K, Abubakar A, et al. Demographic factors associated with HIV infection between low and high prevalence areas in Nigeria, 2015. Pan Afr Med J. 2019;32(Suppl):1. doi:10.11604/pamj.supp.2019.32.1.13330

53. Legarth R, Omland LH, Kronborg G, et al. Educational attainment and risk of HIV infection, response to antiretroviral treatment, and mortality in HIV-infected patients. AIDS. 2014;28(3):387-396. doi:10.1097/QAD.0000000000000032

54. Hargreaves JR, Glynn JR. Educational attainment and HIV-1 infection in developing countries: a systematic review. Trop Med Int Health. 2002;7(6):489-498. doi:10.1046/j.1365-3156.2002.00889.x

55. Neve J-WD, Fink G, Subramanian SV, Moyo S, Bor J. Length of secondary schooling and risk of HIV infection in Botswana: evidence from a natural experiment. Lancet Glob Health. 2015;3(8):e470-7. doi:10.1016/S2214-109X(15)00087-X

56. Dallabetta GA, Miotti PG, Chiphangwi JD, et al. High socioeconomic status is a risk factor for human immunodeficiency virus type 1 (HIV-1) infection but not for sexually transmitted diseases in women in Malawi: implications for HIV-1 control. J Infect Dis. 1993;167(1):36-42. doi:10.1093/infdis/167.1.36

57. Kirunga CT, Ntozi JP. Socio-economic determinants of HIV serostatus: a study of Rakai District, Uganda. Health Transit Rev. 1997;7 (Suppl):175-188.

58. Fortson JG. The gradient in sub-Saharan Africa: socioeconomic status and HIV/AIDS. Demography. 2008;45(2):303-322. doi:10.1353/dem.0.0006

59. Bandura A. Health promotion by social cognitive means. Health Educ Behav. 2004;31:143-164.

60. Exavery A, Boyee D, Lennemann T, et al. Relationship between living arrangements and HIV risk among key and vulnerable populations and the general population in Tanzania. Chicago, USA; 2016. Available from: https://www.abstractstosubmit.com/HIVR4P2016/eposter/main.php?do= YToyOntzOjU6Im1vZHVsIjtzOjY6ImRldGFpbCI7czo4OiJkb2N1bWV udCI7aToyNzA7fQ==\&. Accessed Oct 17, 2019. 


\section{Publish your work in this journal}

HIV/AIDS - Research and Palliative Care is an international, peerreviewed open-access journal focusing on advances in research in HIV, its clinical progression and management options including antiviral treatment, palliative care and public healthcare policies to control viral spread. The manuscript management system is completely online and includes a very quick and fair peer-review system, which is all easy to use. Visit http://www.dovepress.com/testimonials.php to read real quotes from published authors.

Submit your manuscript here: https://www.dovepress.com/hivaids—research-and-palliative-care-journal 